\title{
Analysis of Asian Dust Events in Korea between 1997 and 2005
}

\author{
Soon-Ho Choi, Yongjoo Choi and Young Sung Ghim* \\ Department of Environmental Science, Hankuk University of Foreign Studies, Yongin, Gyeonggi 449-791, Korea \\ *Corresponding author. Tel: +82-31-330-4993, E-mail: ysghim@hufs.ac.kr
}

\begin{abstract}
The characteristics of Asian dust (AD) in Korea between 1997 and 2005 were investigated, focusing on peak 1-hour $\mathrm{PM}_{10}$ concentrations during $A D$ events at seven cities over the Korean Peninsula. The frequency of $A D$ events decreased from Seoul to Busan, indicating the major pathway of $A D$ in Korea was from northwest to southeast. $A D$ events were most frequent in 2001 while peak concentrations during $A D$ events were much higher in 2002. Recent works show that the trajectories from northerly directions increased during the 2000s and later (Chun, 2009; Kim, 2008). In this work, the fraction of trajectories from the northwest was the largest on the whole, although trajectories from each direction varied by city and year. It is presumed that high concentrations of $\mathrm{PM}_{10}$ during $A D$ events are generally associated with trajectories from the northwest rather than from the source region.
\end{abstract}

Key words: Asian dust event, $\mathrm{PM}_{10}$, Peak 1-hour concentration, Backward trajectory, Cluster analysis

\section{INTRODUCTION}

In 2001, Asian dust (AD) was observed on 27 days in Seoul. This number of days is the highest during the past 50 years for which the Korea Meteorological Administration has monitored AD in Seoul (Ghim, 2011). In 2002, massive amounts of AD swept over the Korean Peninsula consecutively on March 21-23 and April 8-10. On March 22, 1-h PM $_{10}$ concentration went up to $2,266 \mu \mathrm{g} / \mathrm{m}^{3}$ at Hannam station at 03:00, and 24-h $\mathrm{PM}_{10}$ concentration reached a record-high value of $1,153 \mu \mathrm{g} / \mathrm{m}^{3}$ at Seongsu station in Seoul. On April 8, both 1-h and 24-h $\mathrm{PM}_{10}$ concentration record highs were replaced with $3,311 \mu \mathrm{g} / \mathrm{m}^{3}$ at Hannam station at 03:00 and $1,510 \mu \mathrm{g} / \mathrm{m}^{3}$ at Guui station (NIER, 2009).

Despite these impacts of $\mathrm{AD}$ at the beginning of the 2000s, scientific efforts to understand the physical and chemical characteristics of AD were rather sparse in Korea. This is contrasted with aggressive efforts of the government that included the implementation of forecasting and warning system and the preparation of comprehensive measures for mitigation of the consequences (KME, 2006). Since the transport routes of $\mathrm{AD}$ are primarily related to its impact along with the inclusion of hazardous substances, their patterns and variations have been an important subject of $\mathrm{AD}$ research (Zhang et al., 2005; Sun et al., 2001). However, only a handful of studies have dealt with this subject in Korea (Kim, 2008; Kim et al., 2008; Kim et al., 2006).

In this work, we studied the characteristics of $\mathrm{AD}$ in Korea by investigating the variations in $\mathrm{PM}_{10}$ concentrations and trajectories of air masses arriving at seven cities, shown in Fig. 1, during the AD events. The target cities encompass major metropolitan areas in Korea, for which the Korean Ministry of Environment (KME) monitors AD outbreaks. This work is distinguished from the previous works such as Kim (2008) in that our study focused on $\mathrm{PM}_{10}$ concentrations rather than meteorology. We analyzed 1-h $\mathrm{PM}_{10}$ instead of 24-h $\mathrm{PM}_{10}$, since 24-h $\mathrm{PM}_{10}$ could include $\mathrm{PM}_{10}$ unrelated to the $\mathrm{AD}$ event depending on the beginning of the event.

\section{DATA AND METHODS}

The AD events in this work for the seven cities between 1997 and 2005 were based on the data released by KME (2008). Total number of $\mathrm{PM}_{10}$ monitoring stations in the seven cities increased from 13 in 1997 to 69 in 2005. The number of stations in Seoul was 8 in $1997,62 \%$ of the total, and 27 in $2005,39 \%$ of the total. $\mathrm{PM}_{10}$ monitoring started in 1998 in Jeonju and 1999 in Gangneung. As a result, $\mathrm{PM}_{10}$ concentrations were available in five cities in 1997 and six cities in 1998 although information on AD events was given for seven cities throughout the study period. In Korea, $\mathrm{PM}_{10}$ is monitored by the $\beta$-ray absorption method. Detailed information on $\mathrm{PM}_{10}$ monitoring can be found 


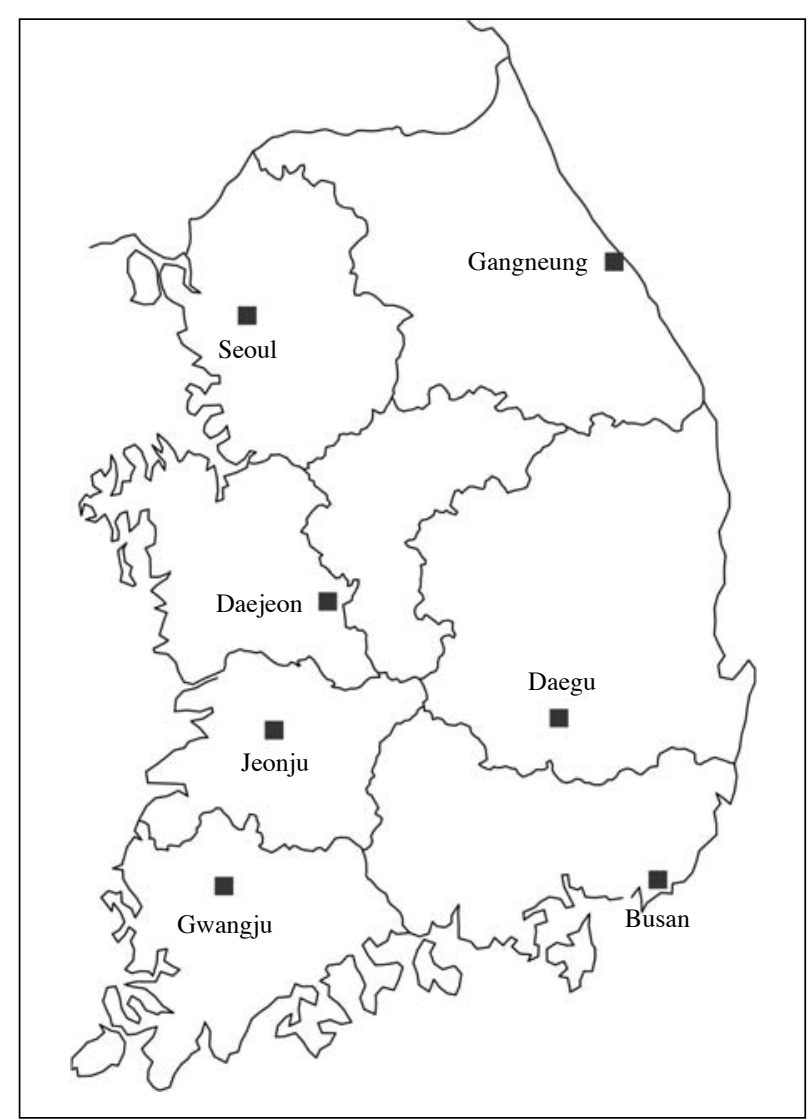

Fig. 1. Locations of the seven cities where the Korean Ministry of Environment monitored the outbreak of Asian dust.

in KME (2011).

We calculated hourly mean concentrations at each city using 1-h concentrations from all monitoring stations in a given city during the AD event. Peak concentration for the city was selected when hourly averages were available for more than $75 \%$ hours a day, that is, 18 hours. It is noted that in Gangneung, there was no station in 1997 and 1998, and only one station since 1999. Therefore, there was no peak concentration at Gangneung even after 1999 , when $\mathrm{PM}_{10}$ concentrations were not available for more than 18 hours a day at this station.

Three-day backward trajectories were calculated, starting at the time of peak concentration at the cities using HYSPLIT (Hybrid Single Particle Lagrangian Integrated Trajectory) 4 Model (Draxler et al., 2009). The trajectories were started at the height of $1.5 \mathrm{~km}$ considering that $\mathrm{AD}$ is typically transported above the boundary layer (Nakajima et al., 2007; Lin, 2001). Trajectories were classified into four groups using the Kmeans clustering method included in the SPSS (Statistical Package for the Social Sciences) 14.0. The num- ber of groups was determined by the hit ratio, which demonstrates how much the grouping by the clustering method coincides with that from a discriminant function (Romesburg, 2004). The hit ratio was $100 \%$ when the number of groups was 3 and 4 and decreased to $77 \%$ when the number increased to 7 . We selected four groups since these groups were more easily interpreted in relation to major source regions of AD.

\section{RESULTS AND DISCUSSION}

\subsection{General Characteristics}

It could be postulated that stronger AD events with high $\mathrm{PM}_{10}$ concentrations would affect a larger area. In order to examine the validity of this presumption, the peak concentrations at the cities in which AD was observed were arranged by event in Fig. 2 in descending order of the highest concentration at each event. As expected, high $\mathrm{PM}_{10}$ concentrations generally occurred when the scale of the event was large. More specifically, AD was observed at all seven cities when the highest concentration was over about $400 \mu \mathrm{g} / \mathrm{m}^{3}$ (denoted by an arrow in Fig. 2), except one event. However, peak concentration was not identified at Gangneung for this event, which could increase the value shown in Fig. 2. During certain events peak concentrations were scattered widely among cities, i.e., peak concentration at one city was very low despite high peak concentrations at other cities.

Table 1 shows the number of AD events by city and year. Total number of $\mathrm{AD}$ events was 43 nationwide, as seen in Fig. 2, but Table 1 shows that the total sum of the events observed by city and year was 189 . This means that the AD events were observed at 4.4 cities on an average. The number of the events decreases from Seoul to Busan, indicating the major route of AD stretched from northwest to southeast over the Korean Peninsula. The number is the lowest in Gangneung because Gangneung is off the major route. Gwangju lies off as well, but the number is not so low since its west location can be directly affected by $\mathrm{AD}$ depending on the transport route.

Fig. 3 shows the peak concentration distributions by city and year. Despite the largest number of $\mathrm{AD}$ events, peak concentrations at Seoul are not much higher than other cities, except two outliers. Outliers are also high at Daegu located in the southeast and the $75^{\text {th }}$ percentile concentration is higher at Jeonju. Variations in concentration levels among cities shown in Fig. 3 are difficult to explain. One exception is Gangneung, where peak concentrations are generally expected to be lower. Concentrations in Seoul, which are not higher than other cities, could be the result of 


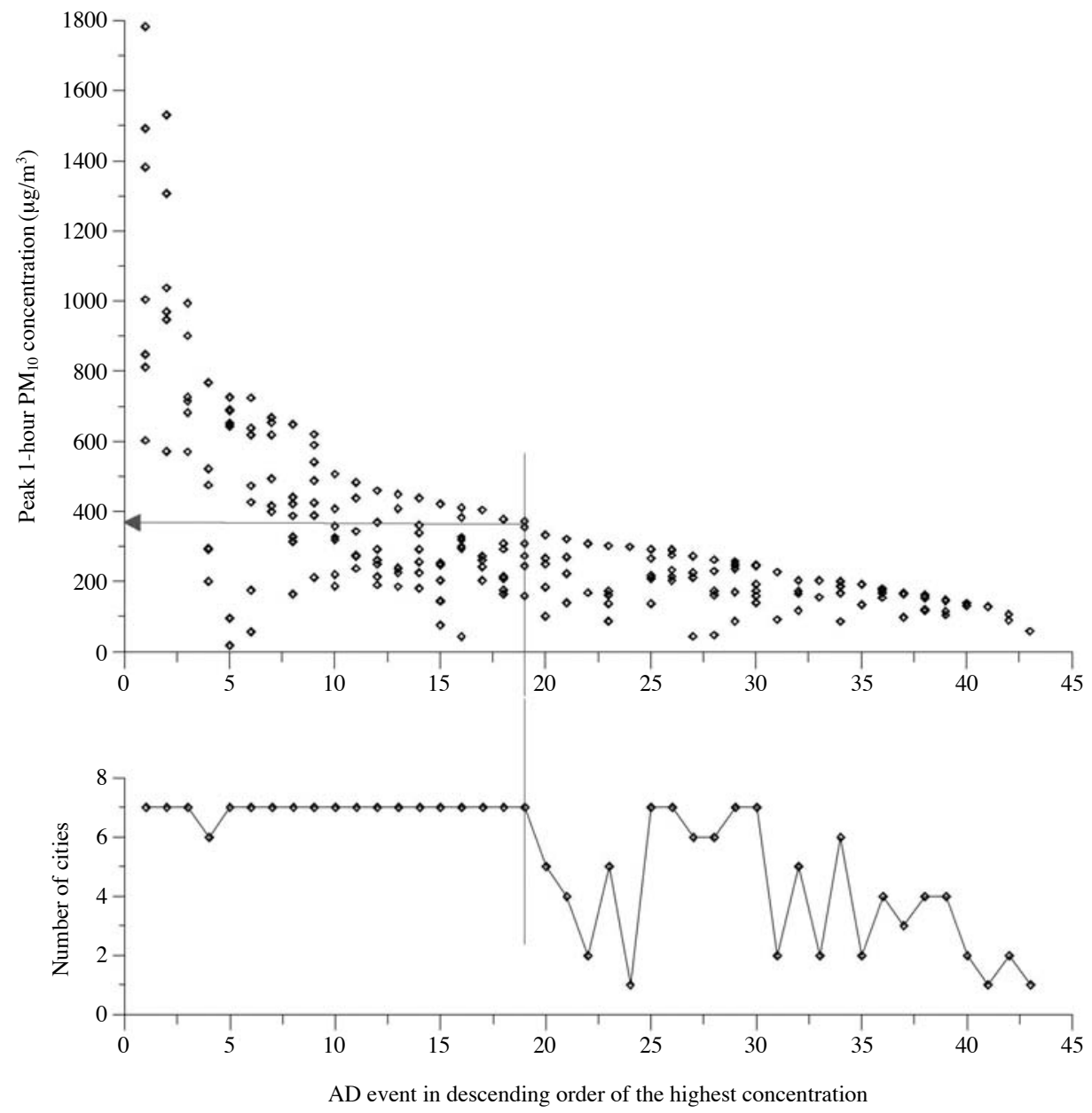

Fig. 2. Peak 1-hour $\mathrm{PM}_{10}$ concentrations at Asian dust (AD) monitoring cities in Korea, arranged in descending order of the highest peak concentration of each AD event. The number of cities where AD was observed is shown at the bottom panel. The left side of vertical line illustrates events which are strong and nationwide.

Table 1. The number of Asian dust events by city and year.

\begin{tabular}{|c|c|c|c|c|c|c|c|c|c|c|}
\hline & 1997 & 1998 & 1999 & 2000 & 2001 & 2002 & 2003 & 2004 & 2005 & Sum \\
\hline Seoul & 1 & 3 & 3 & 6 & 7 & 6 & 2 & 4 & 7 & 39 \\
\hline Daejeon & 1 & 3 & 2 & 4 & 7 & 4 & 1 & 5 & 4 & 31 \\
\hline Jeonju & $-{ }^{a}$ & 2 & 1 & 4 & 8 & 4 & 1 & 4 & 5 & 29 \\
\hline Gwangju & 1 & 2 & 2 & 4 & 6 & 4 & 1 & 5 & 3 & 28 \\
\hline Busan & 1 & 2 & 0 & 5 & 8 & 0 & 0 & 4 & 1 & 21 \\
\hline Deagu & 1 & 2 & 1 & 5 & 6 & 3 & 2 & 5 & 2 & 27 \\
\hline Gangneung & - & - & 1 & 0 & 4 & 3 & 2 & 3 & 1 & 14 \\
\hline Sum & 5 & 14 & 10 & 28 & 46 & 24 & 9 & 30 & 23 & 189 \\
\hline
\end{tabular}

a Not available.

control practices for fugitive dust (KOSAE, 2010). This is because considerable amounts of dust are locally generated during $\mathrm{AD}$ events due to relatively high winds accompanied by AD events (Yuan et al., 2008; Kim and Kim, 2003).
As seen in Table 1, the number of the events is the largest in 2001; however, the concentrations are much higher in 2002. In 1999, high concentrations are comparatively frequent, although the median concentration is low and the number of the events is small (Table 1). 

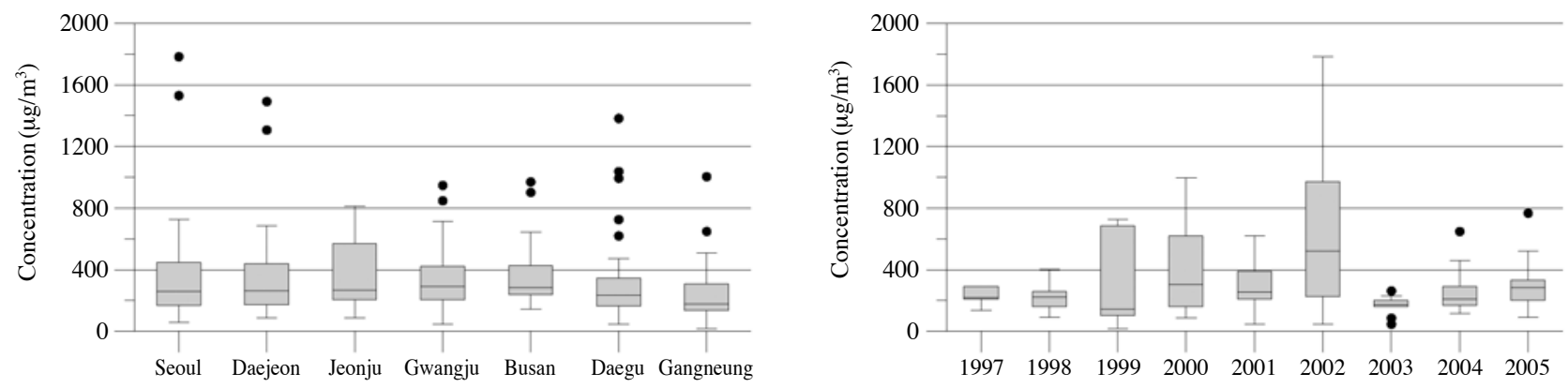

Fig. 3. Distributions of peak 1-hour $\mathrm{PM}_{10}$ concentrations during the Asian dust events by city (upper panel) and year (lower panel). Boxes represent the $75^{\text {th }}, 50^{\text {th }}$, and $25^{\text {th }}$ percentiles from the top. Upper and lower whiskers represent maximum and minimum excluding outliers. Outliers are the data fall below $Q_{L}-1.5\left(Q_{U}-Q_{L}\right)$ or above $Q_{U}+1.5\left(Q_{U}-Q_{L}\right)$, where $Q_{U}$ and $Q_{L}$ are the $75^{\text {th }}$ and $25^{\text {th }}$ percentiles, respectively. Solid circles denote the outliers.

Cluster 1

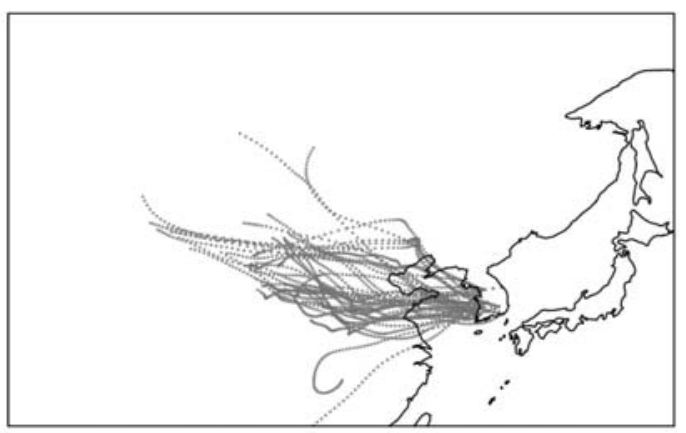

Cluster 3

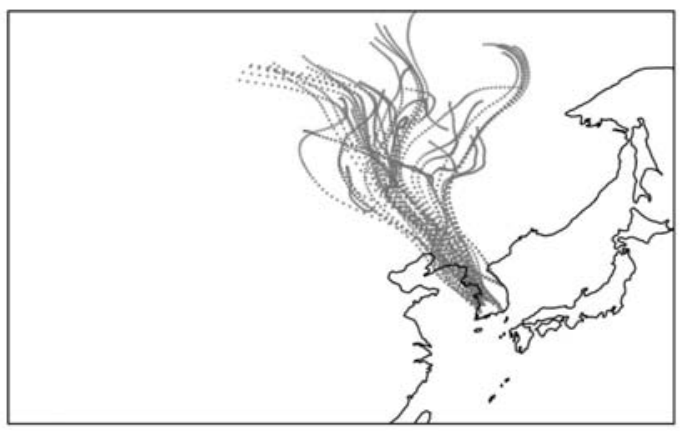

Cluster 2

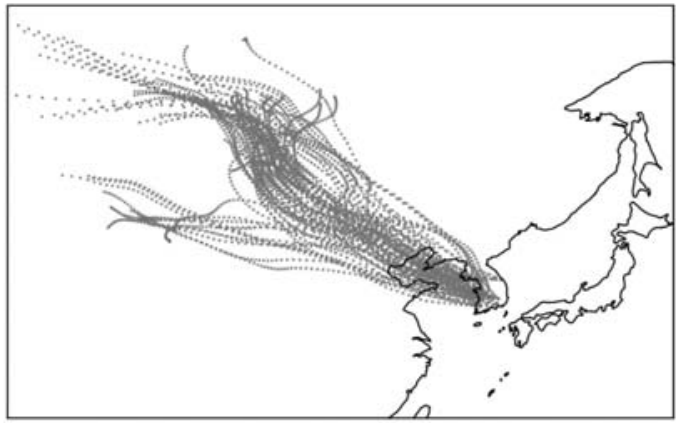

Cluster 4

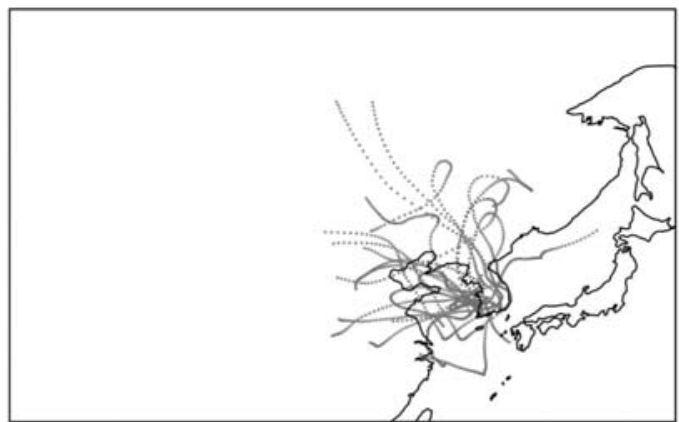

Fig. 4. Clusters of trajectories arriving at the seven cities at the time of peak 1-hour $\mathrm{PM}_{10}$ concentration.

After a huge impact of AD in 2001 and 2002 mentioned earlier, the number of the events dropped in 2003, followed by a slight increase in 2004 and 2005, but the concentration is generally not high except a few outliers.

\section{2 Classification of Trajectories}

Fig. 4 shows the four groups of trajectories classified using the K-means clustering method. The cluster 1 trajectories come from the west, and the cluster 2 trajectories from the northwest. Directions of the cluster
3 trajectories are north-northwest, inclined to north in comparison with those of other clusters. No dominant directions are found for the cluster 4 trajectories. AD sources in the direction of trajectories are Loess Plateau and Badain Jaran Desert for cluster 1, Gobi and Taklimakan Deserts for cluster 2, and Horqin sand land and Inner Mongolian Plateau for cluster 3 (Zhang et al., 2007; Sun et al., 2001).

Table 2 shows the occurrence of clusters by city and year. As a whole, $44 \%$ (83 out of 189) of trajectories during the $\mathrm{AD}$ events are classified as cluster 2, indi- 
Table 2. The frequency of clusters classified by trajectories by city and year.

\begin{tabular}{|c|c|c|c|c|c|}
\hline & Cluster 1 & Cluster 2 & Cluster 3 & Cluster 4 & Sun \\
\hline \multicolumn{6}{|l|}{ (a) By city } \\
\hline Seoul & $10(26 \%)$ & $16(41 \%)$ & $11(28 \%)$ & $2(5 \%)$ & 39 \\
\hline Daejeon & $8(26 \%)$ & $14(45 \%)$ & $6(19 \%)$ & $3(10 \%)$ & 31 \\
\hline Jeonju & $5(17 \%)$ & $14(48 \%)$ & $6(21 \%)$ & $4(14 \%)$ & 29 \\
\hline Gwangju & $7(25 \%)$ & $12(43 \%)$ & $7(25 \%)$ & $2(7 \%)$ & 28 \\
\hline Busan & $5(24 \%)$ & $7(33 \%)$ & $3(14 \%)$ & $6(29 \%)$ & 21 \\
\hline Deagu & $4(15 \%)$ & $13(48 \%)$ & $6(22 \%)$ & $4(15 \%)$ & 27 \\
\hline Gangneung & $2(14 \%)$ & $7(50 \%)$ & $3(21 \%)$ & $2(14 \%)$ & 14 \\
\hline \multicolumn{6}{|l|}{ (b) By year } \\
\hline 1997 & $0(0 \%)$ & $0(0 \%)$ & $5(100 \%)$ & $0(0 \%)$ & 5 \\
\hline 1998 & $7(50 \%)$ & $0(0 \%)$ & $0(0 \%)$ & $7(50 \%)$ & 14 \\
\hline 1999 & $2(20 \%)$ & $3(30 \%)$ & $4(40 \%)$ & $1(10 \%)$ & 10 \\
\hline 2000 & $10(36 \%)$ & $11(39 \%)$ & $4(14 \%)$ & $3(11 \%)$ & 28 \\
\hline 2001 & $11(24 \%)$ & $17(37 \%)$ & $7(15 \%)$ & $11(24 \%)$ & 46 \\
\hline 2002 & $7(29 \%)$ & $17(71 \%)$ & $0(0 \%)$ & $0(0 \%)$ & 24 \\
\hline 2003 & $0(0 \%)$ & $1(11 \%)$ & $8(89 \%)$ & $0(0 \%)$ & 9 \\
\hline 2004 & $1(3 \%)$ & $22(73 \%)$ & $7(23 \%)$ & $0(0 \%)$ & 30 \\
\hline 2005 & $3(13 \%)$ & $12(52 \%)$ & $7(30 \%)$ & $1(4 \%)$ & 23 \\
\hline Sum & $41(22 \%)$ & $83(44 \%)$ & $42(22 \%)$ & $23(12 \%)$ & 189 \\
\hline
\end{tabular}

cating that Gobi/Taklimakan is a major source of AD. It was anticipated that the occurrence of clusters could be affected by the city location with respect to the direction of the cluster. If this be true, the fraction of cluster 2 may be the highest at Seoul, and that of cluster 3 may be the highest at Seoul and Gangneung. However, the fraction of cluster 2 is the highest at all cities (Table 2(a)).

Recently, Kim (2008) investigated the variations in AD trajectories during the past 40 years (1965-2004), dividing the study period into 5-year intervals. He indicated that the number of trajectories from Inner Mongolia and Manchuria increased to 11 during the last 5 years (2000-2004) while it was generally 2 to 3 during the other periods. Chun (2009) showed that the number of trajectories from Inner Mongolia and Manchuria was 7 between 2001 and 2004, and increased to 26 between 2005 and 2008. The trajectories from Inner Mongolia and Manchuria would belong to cluster 3 in this work. We also examined the yearly variations in trajectories in Table 2(b). Although the fraction of cluster 3 is the highest in 2003, that of cluster 2 is the highest in 2002, 2004 and 2005. In fact, it seems that the significance of cluster 2 tends to be increased due to a high fraction (over 70\%) in 2002 and 2004.

The major difference of this work compared with Kim (2008) and Chun (2009) is that we studied the trajectories at the time of peak concentrations. Fig. 5 shows the distribution of peak concentrations by cluster. Peak concentrations of cluster 2 are generally higher; the maximum and $75^{\text {th }}$ percentile concentrations are

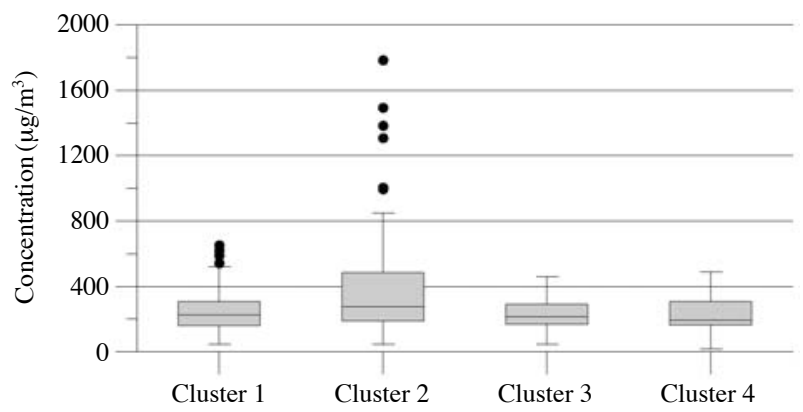

Fig. 5. Distributions of peak 1-hour $\mathrm{PM}_{10}$ concentrations by cluster. Symbols have the same interpretation as Fig. 3.

much higher than those of other clusters along with many outliers above the maximum. On the other hand, those of cluster 3 are not high. We have mentioned that the fraction of cluster 3 is the highest in 2003 in Table 2(b). However, the concentrations are generally low in 2003 (Fig. 3) because the fraction of cluster 2 is low. It is easily seen that trajectories varied even during the same AD event (Kim et al., 2007; Sun et al., 2005). Table 2 and Fig. 5 show that high concentrations of $\mathrm{PM}_{10}$ during the $\mathrm{AD}$ events are generally associated with trajectories of cluster 2 from the northwest, different from the results of other studies which identify source locations.

\section{SUMMAY AND CONCLUSIONS}

The characteristics of AD in Korea between 1997 and 2005 were investigated, focusing on peak 1-h $\mathrm{PM}_{10}$ concentrations at seven cities over the Korean Peninsula. High $\mathrm{PM}_{10}$ peak concentrations generally resulted when the spatial scale of $\mathrm{AD}$ events was large. The number of $\mathrm{AD}$ events was the largest at Seoul and decreased to Busan. It was the lowest at Gangneung due to the location being off the major pathway of $\mathrm{AD}$, from northwest to southeast of the Korean Peninsula. During the study period, peak concentrations during the $\mathrm{AD}$ event were much higher in 2002 while AD events were most frequent in 2001.

Trajectories arriving at the cities at the time of peak concentration were classified into four clusters according to the directions from the Korean Peninsula. As a whole, the fraction of the trajectories from the northwest was the largest, $44 \%$, followed by $22 \%$ each for trajectories from west and north-northwest. This proportion of the clusters was mostly maintained although each fraction varied by city and year. This is different from recent results indicating that the trajectories from northerly directions increased in the 2000s or later (Chun, 2009; Kim, 2008). The main reason for this 
difference is probably because our study was based on the trajectories at the time of peak concentrations. It is interpreted that high concentrations of $\mathrm{PM}_{10}$ during $\mathrm{AD}$ events were generally associated with trajectories from the northwest, rather than with a pathway from the source region.

\section{ACKNOWLEDGEMENT}

This work was supported by the Hankuk University of Foreign Studies Research Fund. We acknowledge the National Institute of Environmental Research (NIER) in Korea for providing $\mathrm{PM}_{10}$ concentrations from National Air Pollution Monitoring Stations.

\section{REFERENCES}

Chun, Y. (2009) Analysis of transport route of Asian dust (2001-2008), personal communication, Asian Dust Research Laboratory, National Institute of Meteorological Research (in Korean).

Draxler, R., Stunder, B., Rolph, G., Stein, A., Taylor, A. (2009) HYSPLIT4 User's Guide, http://www.arl.noaa. gov/documents/reports/hysplit_user_guide.pdf (accessed Jan. 2010).

Ghim, Y.S. (2011) Impacts of Asian dust on atmospheric environment. Journal of Korean Society for Atmospheric Environment 27, 255-271 (in Korean with Abstract in English).

Kim, J. (2008) Transport routes and source regions of Asian dust observed in Korea during the past 40 years (1965-2004). Atmospheric Environment 42, 47784789.

Kim, J.Y., Ghim, Y.S., Song, C.H., Yoon, S.-C., Han, J.S. (2007) Seasonal characteristics of air masses arriving at Gosan, Korea using fine particle measurements between November 2001 and August 2003. Journal of Geophysical Research 112, D07202, doi:10.1029/2005 JD006946.

Kim, K.-H., Kang, C.-H., Lee, J.-H., Choi, K.-C., Youn, Y.-H., Hong, S.M. (2006) Investigation of airborne lead concentrations in relation to Asian dust events and air mass transport pathways. Journal of Aerosol Science 37, 1809-1825.

Kim, K.-H., Kim, M.-Y. (2003) The effects of Asian Dust on particulate matter fractionation in Seoul, Korea during spring 2001. Chemosphere 51, 707-721.

Kim, S.-W., Yoon, S.-C., Kim, J. (2008) Columnar Asian dust particle properties observed by sun/sky radiometers from 2000 to 2006 in Korea. Atmospheric Environment 42, $492-504$.

KME (Korean Ministry of Environment) (2006) Preparation of comprehensive measures for Asian dust including the strengthening of the forecasting and monitoring functions, press release from Air Quality Management Division, March 30 (in Korean).
KME (2008) Status of Asian dust monitoring at seven major cities (1996-2007), press release from Air Quality Management Division, January 9 (in Korean).

KME (2011) Guideline on Installation and Operation of Air Pollution Monitoring Network, Gwacheon, Korea (in Korean).

KOSAE (Korean Society for Atmospheric Environment) (2010) Studies for Revising the Master Plan for the Metropolitan Air Quality Management, Metropolitan Air Quality Management Office, Ansan, Gyeonggi, Korea (in Korean).

Lin, T.-H. (2001) Long-range transport of yellowsand to Taiwan in Spring 2000: observed evidence and simulation. Atmospheric Environment 35, 5873-5882.

Nakajima, T., Yoon, S.-C., Ramanathan, V., Shi, G.-Y., Takemura, T., Higurashi, A., Takamura, T., Aoki, K., Sohn, B.-J., Kim, S.-W., Tsuruta, H., Sugimoto, N., Shimizu, A., Tanimoto, H., Sawa, Y., Lin, N.-H., Lee, C.-T., Goto, D., Schutgens, N. (2007) Overview of the Atmospheric Brown Cloud East Asian Regional Experiment 2005 and a study of the aerosol direct radiative forcing in east Asia. Journal of Geophysical Research 112, D24S91, doi:10.1029/2007JD009009.

NIER (National Institute of Environmental Research) (2009) Studies on Generation Mechanism at the Source Regions and Transport Characteristics by Route of Asian Dust, Final Report of Hankuk University of Foreign Studies (in Korean).

Romesburg, H.C. (2004) Cluster Analysis for Researchers, Lulu Press, NC.

Sun, J., Zhang, M., Liu, T. (2001) Spatial and temporal characteristics of dust storms in China and its surrounding regions, 1960-1999: Relations to source area and climate. Journal of Geophysical Research 106, 1032510333.

Sun, Y., Zhuang, G., Wang, Y., Zhao, X., Li, J., Wang, Z., An, Z. (2005) Chemical composition of dust storms in Beijing and implications for the mixing of mineral aerosol with pollution aerosol on the pathway. Journal of Geophysical Research 110, D24209, doi:10.1029/ 2005JD006054.

Yuan, H., Zhuang, G., Li, J., Wang, Z., Li, J. (2008) Mixing of mineral with pollution aerosols in dust season in Beijing: Revealed by source apportionment study. Atmospheric Environment 42, 2141-2157.

Zhang, X., Gong, S., Zhou, C.H., Liu, H.L., Wang, Y.Q., Niu, T., Yang, Y.Q., Hou, Q. (2007) CMA China sand and dust storm forecasting system \& Asia/Pacific Regional Centre, WMO/GEO Expert Meeting on an International Sand and Dust Storm Warning System, Nov. 7-9, Barcelona, Spain.

Zhang, X.Y., Wang, Y.Q., Wang, D., Gong, S.L., Arimoto, R., Mao, L.J., Li, J. (2005) Characterization and sources of regional-scale transported carbonaceous and dust aerosols from different pathways in coastal and sandy land areas of China. Journal of Geophysical Research 110, D15301, doi:10.1029/2004JD005457.

(Received 22 March 2013, revised 3 May 2013, accepted 9 May 2013) 